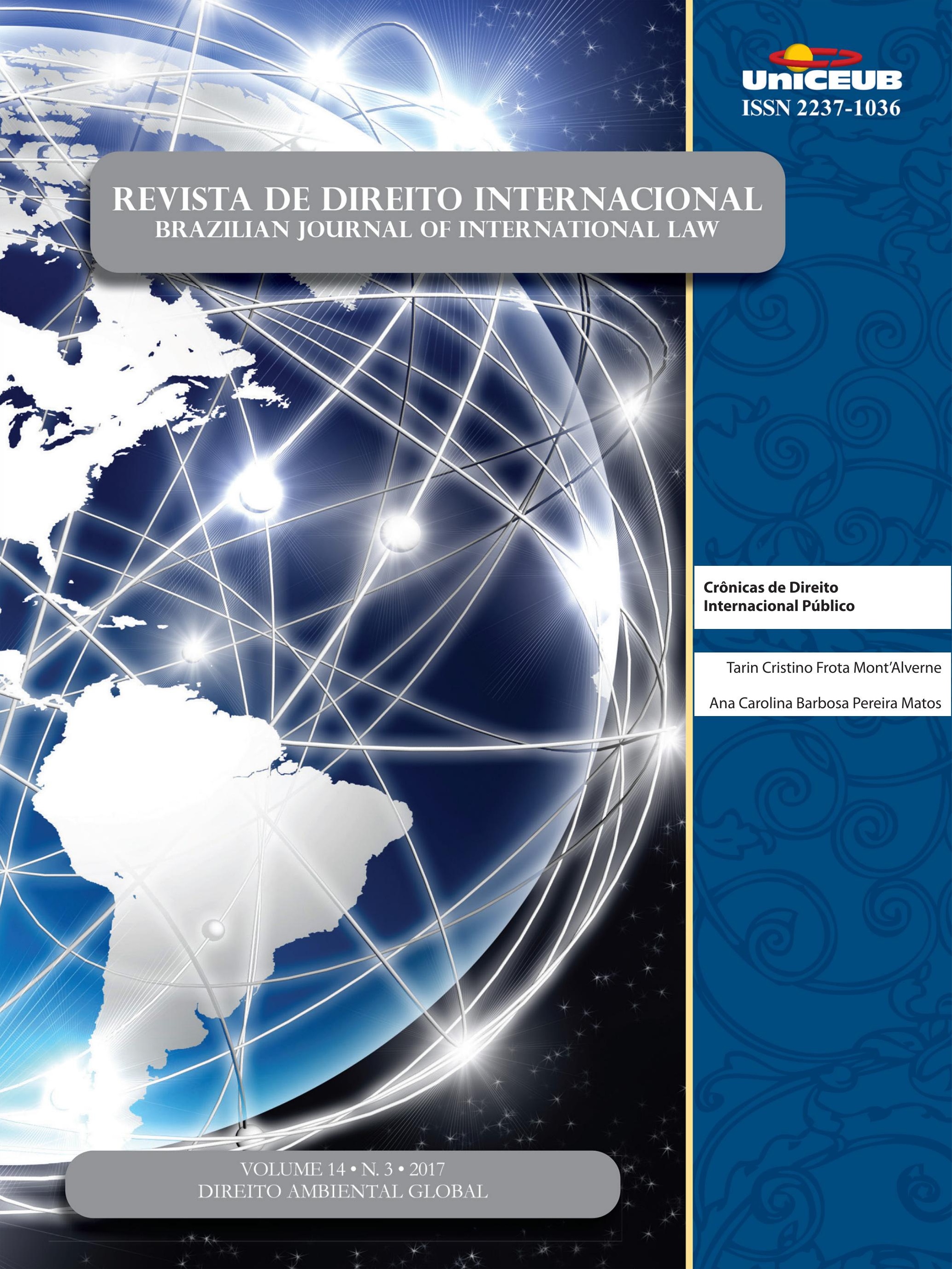




\section{Sumário}

I. Crônicas do Direito Internacional ...............................................1

CRÔNICAS DE DiREITO INTERNACIONAL PÚBLICO ........................................................................ 3

A política australiana de Refúgio e a decisão da Suprema Corte de PAPUA NOVA GUINÉ: A

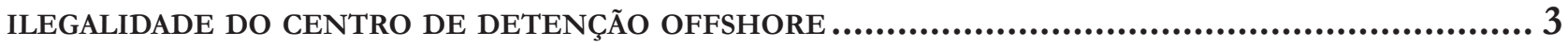

Tarin Cristino Frota Mont'Alverne e Ana Carolina Barbosa Pereira Matos

II. Dossiê especial: Direito Ambiental Global............................................ 7

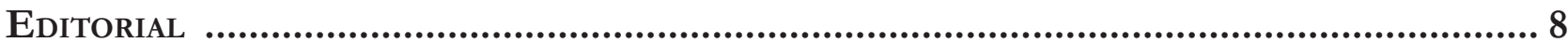

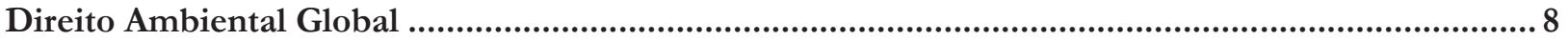

Priscila Pereira de Andrade

Direito Global: UMa TEORIA ADEQUAda PARA SE PENSAR o DiREITO AMBIENTAL? ................10 Arnaud Van Waeyenberge

“Complex is Beautiful": What role for the 2015 Paris Agreement in making the Effective Links within the Climate Regime Complex? .................................................21 Sandrine Maljean-Dubois e Matthieu Wemaëre

UNE ILLUSTRATION DU DROIT GLOBAL, LA LEX MERCATORIA CLIMATIQUE...............................31 Mathilde Hautereau-Boutonnet

OCÉANS ET CHANGEMENTS CLIMATIQUES : RECHERCHER LES INTERACTIONS AU SEIN DE LA FRAGMENTATION DU DROIT INTERNATIONAL

Sophie Gambardella

Une gouvernance globale du Climat par la transparence depuis l'Accord de Paris: Le DROIT GLOBAL DE L'ENVIRONNEMENT COMME SOLFÈGE? .56

Anne-Sofie Tabau 
LA PROGRESSIVE HARMONISATION DES RÈGLES DU PROCÈS ENVIRONNEMENTAL: MANIFESTATION

DE L'ÉMERGENCE D'UN DROIT GLOBAL? ............................................................69

Eve Truilhé-Marengo

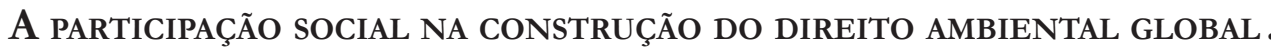
80 Michelle Lucas Cardoso Balbino

A PROTEÇÃo AMBIENTAL COMO EFEITO INDIRETO DO SISTEMA DE GESTÃo DE ENERGIA ISO 50001

Matheus Linck Bassani e Ricardo Serrano Osorio

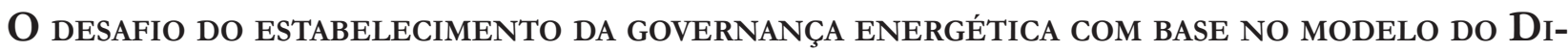
reito Administrativo Global: ESTUdo de CASO DAS ENERgias RENOVÁveis. 122 Alice Rocha da Silva

Othon Pantoja Oliveira de Azevedo

O PRINCÍPIO DA PARTICIPAÇÃo E A CRIAÇÃO E GESTÃo DAS ÁREAS PROTEGIDAS NA PERSPECTIVA DO DIREITO AMBIENTAL GLOBAI

Marcia Dieguez Leuzinger e Solange Teles da Silva

A teoria Ambientalista (GREen theOry) e a COMpetênCia CONSUltiva da CoRTE InTERAmericana de Direitos Humanos: O caso da Colômbia................................................. 148

Eduardo Biacchi Gomes e Ane Elise Brandalise

III. Artigos sobre outros temas....................................................... 160

30 anos do Protocolo de Montreal: Uma história de sucesso do Direito Ambiental

INTERNACIONAL 162

Fernando Rei e Valeria Cristina Farias

MinORIAS NACIONAIS, PROTEÇão INTERNACIONAL E TRANSNACIONALIDADE 182 Ana Maria D'Ávila Lopes e Luis Haroldo Pereira dos Santos Junior

Da relevância dos casos do Desarmamento Nuclear perante a Corte Internacional DE JUSTIÇA 203 Lucas Carlos Lima 
OS CONTROLES DE CONVENCIONALIDADE TRADICIONAL E INTERAMERICANO: INSTITUTOS DISTINTOS OU DUAS FACES DA MESMA MOEDA?

Gilberto Schäfer, Roger Raupp Rios, Paulo Gilberto Cogo Leivas e Jesus Tupã Silveira Gomes

EL SOFT LAW COMO FUENTE DEL DERECHO INTERNACIONAL: REFLEXIONES DESDE LA TEORÍA DE LA COMPLEJIDAD

Rafael Sanz e André Folloni

Ley de rotulación de alimentos de Chile: ¿'Traba comercial o protección de la saLUD?

Nicolás Cobo

IV. RESENHA DE LIVRO.

O CiVILIZAdor gentil das AmÉRICAS: CONSIDERAÇÕes EM TORNO DA OBRA THE HIDDEN HIStory of International LaW in the Americas: Empire and LeGal Networks, de Juan Pablo SCARFI 278

Cicero Krupp da Luz

'Mestizo International Law: A global intelectual history 1842 - 1933' De Autoría de Arnulf Becker-Lorca .283 Jimena Sierra-Camargo

América Latina em Continuidades e rupturas 287 Adriane Sanctis 


\title{
A política australiana de refúgio e a decisão da suprema corte de papua nova guiné: a ilegalidade do centro de detenção offshore*
}

\author{
Tarin Cristino Frota Mont'Alverne** \\ Ana Carolina Barbosa Pereira Matos***
}

\section{A política australiana de Refúgio: Centros de detenção OFFSHORE}

Apesar da Austrália não receber um número tão elevado de solicitantes de refúgio a cada ano, em comparação com países como Estados Unidos e Canadá1 ${ }^{1}$ e de muitos desses solicitantes virem de locais devastados por guerras, o país mantém uma política muito agressiva e restritiva no que tange à entrada ilegal de solicitantes de refúgio em seu território ${ }^{2}$.

As bases do atual regime australiano de refúgio remontam ao ano de 2001, quando o Parlamento revisou as políticas nacionais acerca da matéria e aprovou uma série de medidas legais a fim de restringir a imigração para a Austrália ${ }^{3}$.

Essas medidas foram chamadas de "Solução do Pacífico", que se basearam em quatro ações, das quais merecem destaque em relação a presente pesquisa: a exclusão de mais de 4000 (quatro mil) ilhas australianas da zona de migração, por meio de atos parlamentares - alguns aprovados quando da aproximação de embarcações a certas ilhas particulares -4; e o país transferiu os seus centros de detenção para fora do seu território, onde não estariam submetidos à lei australiana, ou seja, para além do seu mar territorial ${ }^{5}$.

\footnotetext{
** Professora da Faculdade de Direito da Universidade Federal do Ceara (UFC). Possui graduação em Direito pela Universidade de Fortaleza (2001), mestrado em Direito Internacional Público - Universite de Paris V (2004), doutorado em Direito Internacional do Meio Ambiente - Universite de Paris V e Universidade de São Paulo (2008). E-mail : tarinfmontalverne@yahoo.com.br

*** Doutoranda em Direito da Universidade Federal do Ceará (UFC). Mestre em Direito em Ordem Jurídica Constitucional pela Universidade Federal do Ceará (UFC). Especialista em Direito Processual Civil pela Universidade de Fortaleza. Bacharel em Direito pela Universidade de Fortaleza. Professora do curso de Direito do Centro Universitário Estácio do Ceará. E-mail: anacarolina.bpmatos@gmail.com
}

1 Em um comparativo entre países disponibilizado pelo site do Migration Policy Institute, nos anos de 2012 e 2013 (quando foram elaborados os memorandos de entendimento que autorizaram a instalação dos Centros de detenção em Papua Nova Guiné) a Austrália recebeu entre 10977 à 13559 solicitações de refúgio, os Estados Unidos entre 18.881 à 84343 e o Canadá entre 32597 à 22148. Disponível em: < http:/ / www.migrationpolicy.org/programs/ data-hub/charts/refugee-and-asylum-seeker-populations-country-origin-and-destination?wi $\mathrm{dth}=1000$ \&height $=850$ \&iframe $=$ true $>$.

2 É necessário destacar a posição contraditória que a Austrália adota sobre o tema, tendo em vista que ao mesmo tempo em que o país tenta restringir a chegada de solicitantes de refúgio à sua costa em busca do reconhecimento de proteção internacional, participa do programa de reassentamento do Alto Comissariado das Nações Unidas, sendo inclusive um dos maiores per capita dentro do órgão. THE CONVERSATION. FactCheck: Does Australia take more refugees per capita through the UNHCR than any other country? Disponível em: < http://theconversation.com/factcheck-does-australia-take-more-refugees-per-capitathrough-the-unhcr-than-any-other-country-47151> Acesso em: 17 set. 2016.

3 HAMLIN, Rebecca. Let Me Be a Refugee: Administrative Justice and the Politics of Asylum in the United States, Canada, and Australia. New York: Oxford University Press, 2014. p. 55. $4 \mathrm{Na}$ prática esta medida significava que a Austrália não estaria obrigada a processar os pedidos de refúgio de ninguém que ingressasse em uma dessas ilhas. HAMLIN, Rebecca. Let Me Be a Refugee: Administrative Justice and the Politics of Asylum in the United States, Canada, and Australia. New York: Oxford University Press, 2014. p. 56.

5 HAMLIN, Rebecca. Let Me Be a Refugee: Administrative Justice and the Politics of Asy- 
Como os barcos com pessoas tentando obter refúgio na Austrália continuavam a chegar na costa do país, o país editou um memorando de entendimento com Papua Nova Guiné - PNG em setembro de 2012, com o fito de transferir para aquele país os solicitantes de refúgio que tentassem entrar em território australiano, instalando um centro de detenção na ilha Manus, em troca PNG recebeu vantagens econômicas ${ }^{6}$.

Ressalte-se que, ambos os países assinaram e ratificaram a Convenção das Nações Unidas sobre o Estatuto dos Refugiados de 1951 e que, apesar do Estatuto consagrar o princípio do "non-refoulement" (art. 337) e o direito à liberdade de movimento (art. $26^{8}$ ), os solicitantes de refúgio que chegam à Austrália têm sido transferidos coercitivamente para centros de detenção offshore, sendo um deles na ilha Manus em PNG, ali sendo mantidos detidos contra a sua vontade.

Após quatro anos de funcionamento, o centro de detenção da ilha Manus contabilizava mais de 800 homens detidos por tentarem entrar em território australiano para solicitar o reconhecimento de sua condição de refugiados. Ativistas dos direitos humanos criticam duramente as condições das instalações do centro e a própria condição de detentos dessas pessoas .

lum in the United States, Canada, and Australia. New York: Oxford University Press, 2014. p. 56.

6 SUPREMA CORTE DE JUSTIÇA DE PAPUA NOVA GUINÉ. Sentença de 26 de abril, Belden Namah $v$. ministro de assuntos estrangeiros e imigração, o Conselho Nacional Executivo e o Estado independente de Papua Nova Guiné. 2016. Disponível em: < http://www.rilc.org.au/Policy-and-Law-Reform/ManusJudgment. pdf> Acesso em: 8 ago. 2016.

7 Art. 33 - Proibição de expulsão ou de rechaço. 1. Nenhum dos Estados Contratantes expulsará ou rechaçará, de maneira alguma, um refugiado para as fronteiras dos territórios em que a sua vida ou a sua liberdade seja ameaçada em virtude da sua raça, da sua religião, da sua nacionalidade, do grupo social a que pertence ou das suas opiniões políticas. 2. O benefício da presente disposição não poderá, todavia, ser invocado por um refugiado que por motivos sérios seja considerado um perigo para a segurança do país no qual ele se encontre ou que, tendo sido condenado definitivamente por crime ou delito particularmente grave, constitui ameaça para a comunidade do referido país.

8 Art. 26 - Liberdade de movimento. Cada Estado Contratante dará aos refugiados que se encontrem no seu território o direito de nele escolher o local de sua residência e de nele circular, livremente, com as reservas instituídas pela regulamentação aplicável aos estrangeiros em geral nas mesmas circunstâncias.

9 RAMZY, Austin. Papua New Guinea finds australian offshore detention center ilegal. The New York. Times, New York, 26 abr. 2016, Disponível em: < http://www.nytimes.com/2016/04/27/world/ australia/papua-new-guinea-asylum-seeker.html?_r=0 $>$ Acesso em: 11 ago. 2016.
Em torno de metade dos detidos na ilha tiveram o seu pedido de refúgio aceito, mas até abril de $2016^{10}$ apenas oito deles haviam sido reassentados, os demais permaneciam detidos, sob alegações de que o governo de PNG precisava realizar a transferência desses refugiados para as cidades de forma cautelosa ${ }^{11}$.

Diante das críticas de desrespeito aos direitos humanos e de ilegalidade de detenção dos solicitantes de refúgio no território de Papua Nova Guiné foi proposta a ação de no 84/2013, por Belden Namah, membro do parlamento de Papua Nova Guiné e líder da oposição, contra o ministro de assuntos estrangeiros e imigração, o Conselho Nacional Executivo e o Estado independente de Papua Nova Guiné ${ }^{12}$.

O objetivo principal da ação ${ }^{13}$ era o reconhecimento de que as transferências de suplicantes de refúgio e refugiados enviados para Papua Nova Guiné pelo governo australiano e detidos no centro de realocação da ilha Manus eram contrárias ao direito constitucional de liberdade pessoal garantido na seção 42 da Constituição daquele país.

Em 26 de abril de 2016, a Suprema Corte de Papua Nova Guiné se posicionou no sentido de considerar inconstitucional e, consequentemente, ilegal a transferência e detenção forçada de solicitantes de refúgio no centro de detenção da ilha.

O acordo internacional firmado entre a Austrália e Papua Nova Guiné fere frontalmente cláusulas do Estatuto dos refugiados, contudo, a cláusula que regula a solução de dissídios referentes à Convenção de 1951, prevê que para a instauração de uma controvérsia em relação ao referido instrumento é necessária a submissão de um pedido por um dos países Partes perante a

10 A referência à tal data deve-se ao fato de que foi no mês de Abril de 2016 que a Suprema Corte de Papua Nova Guiné proferiu a decisão analisada nesta crônica.

11 RAMZY, Austin. Papua New Guinea finds australian offshore detention center ilegal. The New York Times, New York, 26 abr. 2016. Disponível em: < http://www.nytimes.com/2016/04/27/world/ australia/papua-new-guinea-asylum-seeker.html?_r $=0>$. Acesso em: 11 ago. 2016.

12 Acrescente-se que, por tratar a ação da repercussão interna do acordo firmado entre Austrália e PNG, a Austrália não é parte da ação.

13 SUPREMA CORTE DE JUSTIÇA DE PAPUA NOVA GUINÉ. Sentença de 26 de abril, Belden Namah $v$. ministro de assuntos estrangeiros e imigração, o Conselho Nacional Executivo e o Estado independente de Papua Nova Guiné. 2016. Disponível em: Disponível em: < http://www.rilc.org.au/Policy-and-Law-Reform/ ManusJudgment.pdf $>$. Acesso em: 8 ago. 2016. 
Corte Internacional de Justiça, o que até o momento ainda não foi proposto no tocante à política australiana de refúgio.

Logo, a decisão da Suprema Corte de Papua Nova Guiné é de grande relevância para o direito internacional dos refugiados, pois por meio de um Tribunal nacional foi realizado um controle de legalidade de uma política que, ao invés de promover o direito dos refugiados, tem desrespeitado seus direitos mais básicos, tendo tal controle se fundamentado diretamente em instrumentos internacionais de proteção de direitos humanos.

\section{O PRINCÍPIO DA DIGNIDADE DA PESSOA HUMANA COMO CRITÉRIO DE VALIDADE DAS POLÍTICAS INTERNACIONAIS SOBRE REFÚGIO}

A referida decisão, além do importante impacto para a política interna de Papua Nova Guiné e da Austrália - uma vez que determinou que providências fossem tomadas pelos dois países para o fechamento definitivo do centro de detenção da ilha Manus ${ }^{14}$-, também merece destaque no âmbito internacional, pois analisa a questão pelo aspecto do atendimento de tratados e convenções internacionais de direitos humanos, contribuindo para

14 Sobre o tema, importante destacar que apesar da decisão proferida pela Suprema Corte de Papua Nova Guiné em abril de 2016, a Austrália em um primeiro momento rejeitou a decisão, alegando que não teria sido parte da ação e que, portanto, não permitiria a entrada dos refugiados e solicitantes de refúgio em seu território, mas depois acabou concordando com um plano de reassentamento em conjunto com o governo de PNG. Finalmente, em 31 de Outubro de 2017 o Centro de detenção foi oficialmente fechado. A Austrália em um acordo com Papua Nova Guiné ofereceu um local provisório para a realocação das aproximadamente 600 pessoas que se encontravam no local - das quais em torno de 440 já tinham sido reconhecidas como refugiadas, aguardando apenas o seu reassentamento para um terceiro país -, a fim de que estes aguardem as providências de reassentamento que tem sido negociadas entre a Austrália e o governo dos Estados Unidos - que aceitou receber alguns dos refugiados. No entanto, a maioria dos detidos se recusa a deixar o antigo centro de detenção, por temerem por sua segurança nestes "centros de trânsito" - como tem sido chamados os locais para os quais os antigos detentos aguardarão o seu reassentamento - e em razão da falta de condições dignas para a sua acomodação nestes centros, representantes das Nações Unidas afirmam que estes "centros de trânsito" não estão prontos, estando ainda em obras e sem espaço suficiente para acomodar todos os antigos detentos. MEIXLER, Eli. What to know about the asylum seeker standoff on Manus Island. Time, Manus island, 6 nov. 2017. Disponível em: $<$ http://time.com/5006776/manus-island-asylum-seekers-australia/>. Acesso em: 22 nov. 2017. as discussões no que tange a propositura de soluções para o problema dos refugiados em todo o mundo.

Ademais, na atualidade a globalização, com sua velocidade para a constituição de relações jurídicas, promove uma relativização espacial em que cada vez mais são realizadas atividades extraterritoriais, provocando uma constante internacionalização do direito. Logo, não é incomum tribunais nacionais serem forçados a se posicionar indiretamente sobre questões de direito internacional, não se podendo desprezar jurisprudências de âmbito nacional como fontes do direito internacional.

A decisão da Suprema Corte de PNG enfrentou três questões principais para concluir pela ilegalidade do centro de detenção para solicitantes de refúgio em seu território $^{15}$ : (i) a constitucionalidade da transferência e permanência no centro de detenção dos solicitantes de refúgio; (ii) se a seção 1 da emenda constitucional de $\mathrm{n}^{\circ}$ 37 (cidadania) - editada para a legalização do acordo firmado entre os dois países para a detenção de solicitantes de refúgio em PNG - seria inválida; (iii) e, logo, se a seção 42 (1) (ga) da Constituição de PNG - introduzida pela referida emenda constitucional - seria aplicável aos solicitantes de refúgio.

Além de aspectos formais - relacionados ao processo legislativo de PNG -, a Suprema Corte daquele país fundamentou a análise das questões referidas em um importante critério material, a aderência e o respeito dos dispositivos atacados ao princípio da dignidade da pessoa humana e aos instrumentos internacionais de direitos humanos ${ }^{16}$.

O Tribunal concluiu que os requisitos formais para a aprovação de uma emenda constitucional conforme disposto na Carta Magna do país haviam sido satisfeitos, no entanto, no que tange aos requisitos materiais a emenda não atenderia à análise do disposto na seção 38(5) da Constituição de PNG, "ser razoavelmente justificável em uma sociedade democrática tendo um res-

15 SUPREMA CORTE DE JUSTIÇA DE PAPUA NOVA GUINÉ. Sentença de 26 de abril, Belden Namah $v$. ministro de assuntos estrangeiros e imigração, o Conselho Nacional Executivo e o Estado independente de Papua Nova Guiné. Disponível em: < http://www. rilc.org.au/Policy-and-Law-Reform/ManusJudgment.pdf $>$. Acesso em: 8 ago. 2016.

16 SUPREMA CORTE DE JUSTIÇA DE PAPUA NOVA GUINÉ. Sentença de 26 de abril, Belden Namah $v$. ministro de assuntos estrangeiros e imigração, o Conselho Nacional Executivo e o Estado independente de Papua Nova Guiné. 2016. Disponível em: <http:// www.rilc.org.au/Policy-and-Law-Reform/ManusJudgment.pdf $>$. Acesso em: 8 ago. 2016. 
peito apropriado pelos direitos e dignidade da humanidade, de acordo com as circunstâncias do momento em que a lei seja elaborada e considerando as questões previstas na seção 39(3) da Constituição"17.

A seção 39(3), dentre outras questões, aponta como pontos relevantes de observância: a declaração universal dos direitos humanos e qualquer outra declaração, recomendação ou decisão da Assembleia Geral das Nações Unidas concernente aos direitos humanos e liberdades fundamentais, bem como a Convenção europeia de direitos humanos e liberdades fundamentais e quaisquer outras convenções internacionais, acordos ou declarações relacionadas aos direitos humanos e liberdades fundamentais ${ }^{18}$.

O critério material introduzido pela decisão da Suprema Corte de PNG, com base na Constituição daquele país, para a análise da legalidade do acordo de cooperação internacional celebrado entre PNG e Austrália, impõe uma análise temporal, de acordo com as circunstâncias do momento em que o acordo foi elaborado.

Considerando-se o momento em que foram firmados os memorandos de entendimento entre Austrália e Papua Nova Guiné, anos de 2012 e 2013, para a instalação do centro de detenção da ilha Manus, é inegável o desenvolvimento e a consolidação do direito internacional dos refugiados, bem como da prevalência do princípio da dignidade da pessoa humana como um dos principais norteadores das sociedades democráticas dos dias atuais, o que não justifica a relativização de direitos e princípios garantidores dos direitos humanos, em prol do atendimento de interesses políticos de certos países.

Neste sentido, merece destaque a publicação realizada pelo Alto Comissariado das Nações Unidas para Refugiados - ACNUR, no ano de 2012, acerca das diretrizes para a detenção de solicitantes de refúgio, que consagrou, dentre outros critérios que: o direito de solicitar o reconhecimento da condição de refugiado deve ser respeitado; os direitos à liberdade e à segurança da pessoa e a liberdade de ir e vir se aplicam aos solicitantes de refúgio; a detenção não deve ser arbitrária e toda decisão de deter alguém deve estar baseada em

17 SUPREMA CORTE DE JUSTIÇA DE PAPUA NOVA GUINÉ. Sentença de 26 de abril, Belden Namah v. ministro de assuntos estrangeiros e imigração, o Conselho Nacional Executivo e o Estado independente de Papua Nova Guiné. 2016. Disponível em: <http:/ / www.rilc.org.au/Policy-and-Law-Reform/ManusJudgment.pdf $>$. Acesso em: 8 ago. 2016.

18 PAPUA NOVA GUINÉ. Constituição, 1975. uma avaliação das circunstâncias particulares da pessoa; a detenção indefinida é arbitrária e a lei deve estabelecer limites máximos ao período de detenção; as decisões para deter ou prolongar a detenção devem estar sujeitas às garantias processuais mínimas; as condições de detenção devem ser humanas e dignas ${ }^{19}$.

Observa-se que, ao tempo da implementação da política de detenção de requerentes de refúgio pela Austrália, o direito internacional já tratava da detenção de solicitantes e de refugiados como medida excepcional, haja vista que resta consagrado no art. $14, \mathbb{\Omega} 1^{\circ}$, da Declaração Universal de Direitos Humanos, o direito de procurar e de gozar de refúgio em outros países. Assim, a solicitação do reconhecimento da condição de refugiado não é um ato ilegal, não devendo por si só ensejar uma ordem de detenção dessas pessoas.

Ademais, tendo em vista o caráter amplo da noção de dignidade da pessoa humana, infere-se das diretrizes expostas a sua estreita correlação com tal princípio, sendo tais critérios utilizados justamente para resguardar a dignidade de solicitantes de refúgio e de refugiados.

Um acordo que coloca em risco, ao invés de promover, as garantias consagradas no Estatuto dos refugiados não pode ser justificado ${ }^{20}$. Assim, a tendência atual de acordos internacionais entre países para a transferência de responsabilidades, deve ter como preceito básico o fato de, pelo menos, o país receptor dos refugiados conceder a estes as mesmas garantias mínimas que teriam no país de seu destino original.

Em tempos de acordos de cooperação internacional em matéria de refugiados ${ }^{21}$ na tentativa de se solucionar a crise internacional instaurada, a decisão da Suprema Corte de Papua Nova Guiné contribui para o debate quanto ao controle de legalidade de tais políticas, propondo como critério norteador de tais acordos o valor máximo da dignidade da pessoa humana, a fim de garantir o respeito às diretrizes mínimas que refletem o objetivo da Convenção das Nações Unidas sobre o Estatuto dos Refugiados.

19 ACNUR, Directrices del ACNUR sobre los criterios y estándares aplicables con respecto a la detención de solicitantes de asilo, 1999.

20 FOSTER, Michelle. The implications of failed 'Malaysian solution': The Australian High Court and refugee responsibility sharing at international law. Melbourne Journal of International Law, v. 13, n. 1, p. 422, 2012.

21 Além do caso em análise, não se deve olvidar do acordo firmado entre a Turquia e países da União Europeia em 2016. 
Para publicar na Revista de Direito Internacional, acesse o endereço eletrônico www.rdi.uniceub.br ou www.brazilianjournal.org.

Observe as normas de publicação, para facilitar e agilizar o trabalho de edição. 